\title{
LA EDUCACIÓN SUPERIOR EN LAS INSTITUCIONES DE LAS FUERZAS ARMADAS Y DE ORDEN
}

\author{
Juan Carlos Salgado*
}





\section{LA EDUCACIÓN SUPERIOR EN LAS INSTITUCIONES DE LAS FUERZAS ARMADAS Y DE ORDEN}

\section{INTRODUCCIÓN}

Las características de los tiempos modernos, junto con el desafío para todos los chilenos de enfrentar el nuevo milenio con un desarrollo integral, duradero y sustentable, determinan que las relaciones de los distintos grupos sociales cobren una creciente importancia. Dichas relaciones están establecidas en el plano constitucional, académico y de las comunicaciones. Estos puntos de encuentro permiten el intercambio de ideas y la expresión de opiniones y puntos de vista, lo que conduce a un mayor conocimiento y una más efectiva integración.

El espacio académico, tradicionalmente, ha constituido un elemento de aproximación mediante el cual se llevan a cabo estudios humanísticos, científicos y tecnológicos referidos a diversos ámbitos del conocimiento. A partir de la promulgación de la Ley $\mathrm{N}^{\circ} 18.962$ "Orgánica Constitucional de Enseñanza" (LOCE), en 1990, los planteles de Educación Superior de las Fuerzas y de Orden han pasado a formar parte activa del Sistema de Educación Superior del país. Ello ha permitido que hoy podamos mirar con optimismo la existencia de una real participación e integración entre estos establecimientos y las universidades estatales, privadas, los institutos profesionales y los centros de formación técnica. Ello ha redundado, además, en un real intercambio académico entre civiles y militares.

De lo anterior se desprende que, actualmente, algunas instituciones de la Defensa Nacional realicen programas de posgrado -para su propio personal y para la especialización de civiles- y se encuentren participando en actividades propias del sistema educativo terciario como, por ejemplo, en el Proyecto de Diseño de un Sistema de Información para la Educación Superior, que lleva adelante la 
Comisión Nacional de Acreditación y Pregrado (CNAP) y en el Consejo Superior de Educación, con la finalidad de asegurar la calidad de educación-superior, media y básica- que se imparte en el país.

El Ejército se encuentra desarrollando programas de posgrado, por ejemplo las maestrías en Ciencias Militares con mención en Gestión y Planificación Estratégica, en Operaciones de Paz, Conflicto y Negociación Internacional, entre otras; también un diplomado en Planificación y Dirección en Prevención y Manejo de Desastres. Todos ellos se llevan a efecto en la Academia de Guerra de esa institución. Asimismo, un número variable de oficiales realizan anualmente estudios de posgrado en distintas universidades del país, en áreas tales como: Logística, Relaciones Internacionales, Ciencia Política y Recursos Humanos.

Por otra parte, es destacable el hecho de que los jóvenes que hoy egresan de la Escuela Militar lo hacen con el grado de Licenciado en Ciencias Militares, conjuntamente con el grado de Oficial de Ejército. Esto ha sido posible gracias a los convenios que se han suscrito con la Pontificia Universidad Católica de Chile y la Universidad Diego Portales, dentro del Plan de Modernización Institucional.

La Armada, contando con características similares al resto de las instituciones, presenta también condiciones particulares que la distinguen, como el hecho que el proceso de formación y especialización lo imparte exclusivamente al personal que integrará o que integra sus dotaciones. No obstante, la educación naval se encuentra absolutamente integrada al Sistema de Educación Superior del país, lo que se refleja en el desarrollo de gran cantidad de actividades con diversos planteles, producto de numerosos convenios suscritos con universidades, institutos profesionales y centros de formación técnica. Dentro de estas actividades se destacan programas de maestrías (Dirección de Empresas, Ciencias Militares, Seguridad y Defensa, Ingeniería Mecánica, Salud Pública, Ingeniería Civil Informática, Educación, Humanidades, entre otros) además de diplomados y seminarios en Aministración de Recursos Humanos, Tecnologías de la Educación e-learning, Docencia en Educación Superior y otros. 
La Fuerza Aérea, a través de sus institutos, constituye una alternativa académica de calidad para los jóvenes que dan término a su proceso de enseñanza media. En el marco de los nuevos cambios y desafíos que enfrenta la sociedad chilena, los diferentes componentes del sistema antes mencionado orientan el accionar de sus procesos hacia la consecución de sus propios objetivos. La vinculación con entidades de formación superior y las alianzas estratégicas con universidades han permitido crear un puente de comunicación con la sociedad. En esta perspectiva, como una forma de complementar la educación adquirida en escuelas y academias, personal de esta institución se encuentra realizando maestrías en las áreas de Recursos Humanos y Administración en la Universidad Gabriela Mistral, y en Ciencia Política en la Universidad de Chile. Igualmente, la Fach ha firmado un convenio con la Universidad de Concepción sobre un Programa de Intercambio Científico Tecnológico.

Por su parte, Carabineros de Chile, dentro de su desarrollo docente, participa activamente en este sistema terciario a través de diversas actividades. Actualmente imparte los siguientes estudios superiores en la Academia de Estudios Policiales -donde también pueden participar civiles-: Magíster en Ciencias Policiales, Magíster en Seguridad y Prevención Social y diplomado en Seguridad Integral de Empresas. Además, ha suscrito un conjunto de convenios con universidades estatales y privadas con la finalidad de capacitar a miembros de su institución en estudios relacionados con las carreras de Derecho y Auditoría en la Universidad de Chile. Finalmente, en la Pontificia Universidad Católica de Chile: Magíster en Derecho Internacional, Programa de Investigación Académico-Universitario en Temas Criminólogos y Diplomado en Preparación y Evaluación de Proyectos.

Todo el proceso descrito, junto con permitir la integración académica entre civiles y militares en el país, ha acrecentado la calidad intelectual de los miembros de las instituciones de la Defensa Nacional, en directa relación con el Proyecto de Reforma y Modernización del Estado y las mayores exigencias que éste le demanda en el plano mundial.

Dentro de la proyección del Estado de Chile en esta era de la globalización, las Fuerzas Armadas y de Orden juegan un importante 
rol en el contexto internacional, lo que se ha visto reflejado a través de Misiones Permanentes de la Cancillería y en Misiones de Mantenimiento de la Paz bajo mandato de la Organización de las Naciones Unidas. 